\title{
How to develop professionally important soft-skills for IT-professionals by means of physical education?
}

\author{
ANDRII ANDRES \\ Department of Physical Education, Lviv Polytechnic National University, Lviv, Ukraine
}

\begin{abstract}
Information on features necessary for productive professional work is interesting for both scientists and employers. Single systematized contradictory data don't allow to improve training programs, make effective training programs for IT-specialists for productive professional work. Goal - identify critical important, important and desirable professional qualities for IT-specialists, according to the data of literature determine the most important means of their effective development. Methods, participants, and organization. The study participants were 142 students who study at the university in the 3rd year and have experience in the specialty "information technology" for at least 2 years. Students evaluated soft-skills (on a 4-point system) by the degree of importance for the successful work of IT-professionals. The results were calculated in\%, and the reliability of the discrepancies between neighbouring groups of indicators was determined using the $\mathrm{X} 2$ criterion. Results. It has been determined that emotional intelligence is a crucial quality for IT professionals, as well as leading and desired skills. Whereas the leading skills are studying ability and strive for selfeducation and self-improvement; independent decision making and problem solving; establishing communication and team-working; creativity, attention to details, and adaptiveness. An adequate level of physical conditions and leadership are regarded as desirable. The level of importance of psychophysical parameters for IT professional's work efficiency has been determined. It has been determined, that means of physical activities as mental fitness (hatha yoga, Bodyflex and Pilates), sports games (and other measures for promote agility) have worked well in the development of cognitive qualities of students. To form professionally important skills, IT-specialists have been recommended to use aids to promote agility and mental fitness, to reinforce the workload on physical education sessions, increase the number of academic classes on physical education up to 3 per week, or supplement academic activities with sports. In professional literature, there has been found no datum on the type of motor activity that encourages forming a number of leading professionally important qualities.
\end{abstract}

Keywords: Physical education; Physical activity; Psychophysical parameters; Emotional intelligence; Agility; Endurance.

\section{Cite this article as:}

Andres, A. (2021). How to develop professionally important soft-skills for IT-professionals by means of physical education?. Journal of Human Sport and Exercise, 16(3), 652-661. https://doi.org/10.14198/ihse.2021.163.14

Corresponding author. Department of Physical Education, Lviv Polytechnic National University, Lviv, Ukraine. https://orcid.org/0000-0002-1472-9009

E-mail: andres-a@ukr.net

Submitted for publication February 13, 2020.

Accepted for publication April 03, 2020.

Published July 01, 2021 (in press May 13, 2020).

JOURNAL OF HUMAN SPORT \& EXERCISE ISSN 1988-5202

(c) Faculty of Education. University of Alicante.

doi:10.14198/jhse.2021.163.14 


\section{INTRODUCTION}

There is no company that can do without computer specialists. That is why the demand for highly skilled professionals in the field of information technology (IT) is steadily increasing. Therefore, the system of higher education bears the responsibility of promoting the quality training of highly skilled professionals capable of participating competitively in the current labour market. Under such circumstances, there is a growing need in forming professionally important personal qualities while studying at higher educational establishments (HEE). Therefore, information about the features needed for effective professional work is of interest to both scientists and employers.

Some data on important qualities for specialists from various professions are readily available in the professional literature: military (Hlazunov, 2016; Lisowski et al.,2013) and railway (Pichurin, 2014) personnel, as well as economists (Salatenko at al., 2015). There is partial information (Ostapenko, 2015) on professionally important qualities for IT-specialists. Literature database search has been divided into groups: one group of specialists is focused on technical skills, another - on psychophysical qualities, while all the rest - on personal traits important for successful specialist's professional realization. It has been proved in the scientific publications that working efficiency of IT-specialists depends on their leadership skills and creativity (Collin et al, 2018), goodwill and responsibility (Waraporn, 2015). The degree of importance of individual qualities has been determined by the specialists. It has been introduced (Kappelman, 2016) the way requirements for the professional skills vary depending on the improvement of their qualification level. Systems for the evaluation of the degree of professional competence for IT-specialists have been developed on the basis of importance of the characteristics (Danaher et al 2016; Kranov et al 2011). These developments provide adjustments in the educational process at higher educational establishments (HEE). However, unfortunately these developments do not refer to the process of physical education (PE).

Importance of high mental performance, as well as rate of mental processes for IT-specialists is often referenced by professionals. Therefore, only few sources (Ostapenko, 2015) identify physical skills (endurance and agility) as important ones for successful professional career of IT-specialists. Even though, the level of development of psychophysical skills is linked to the level of development of physical qualities (Pichurin, 2018).

Development of physical and psychophysical abilities, as well as personal qualities has the potential to contribute to physical education and sports. Such classes provide psycho-emotional relief, establish communication, and improve the flexibility of mental processes (Salatenko et al, 2015; Kostyunin, 2014; Kozina et al, 2014). Visual-motor response; span, distribution, concentration and stability of attention; operative thinking; operational and long-term memory (Ostapenko et al 2015) - all of them are the most important psycho-physiological qualities of IT-specialists. Dexterity exercises are considered to be effective means to development of professionally important psychophysical skills of IT-specialists (Pichurin, 2018; Andres, 2018).

Psychophysical training is regarded (Pichurin, 2014) by professionals as part of a physical educational process for students. Its tools should be aimed at the formation of specialized psychological and psychophysical characteristics important for building the future career.

Single systematized contradictory data, as well as lack of information on the degree of importance of IT specialist's qualities don't allow to identify the level of competence HEE graduates, appoint candidates, improve training programs at HEE, make effective training programs for IT-specialists for productive 
professional work, resist professional burnout. It does not contribute to increasing the competitiveness of Ukrainian specialists in the world labour market.

Goal - identify very important, important and desirable professional qualities for IT-specialists, according to the data of literature determine the most important means of their effective development.

\section{MATERIALS AND METHODS}

\section{Participants}

The study participants were 142 students who study at the university in the 3 rd year and have experience in the specialty "information technology" for at least 2 years $(2.82 \pm 0.56)$. All participants are male, the age of the participants is $20.28 \pm 0.46$ years.

\section{Measures \\ Questionnaire}

We designed a questionnaire consisting of 3 parts. In the first of them, the introductory note, they indicated who and for what purpose the survey was conducted. The second part contained a table listing 28 qualities and options for answers. The list was made by us at the previous stage of the study (Andres et al, 2019) on the basis of literature data. Each participant had to evaluate each of our qualities according to the degree of importance for the successful professional work of specialists in the specialty "Information Technology". For this purpose, students circled in each row a number corresponding to their chosen answer (3-very important, 2-important, 1-desirable, 0 -not important) in the corresponding box against each quality. The second part of the questionnaire - passport containing questions about age, seniority of work in the specialty.

\section{Procedures}

The survey was conducted by the teacher before the start of the physical education class. The participants were informed that the surveys were being conducted for scientific purposes. Students were introduced to the rules of filling in the questionnaire and answered the questions. All students agreed to participate in the survey.

\section{Analysis}

The results were calculated in \%, and the reliability of the discrepancies between neighbouring groups of indicators was determined using the $x 2$ criterion.

\section{RESULTS}

The research shows that among the qualities important for IT professionals, it is possible to distinguish at least three groups: critical, leading and desirable (Figure 1). Significant differences were observed between the values of these three groups $(p<.05)$. Emotional intelligence appeared to be the crucial quality for ITspecials $(78.0 \%)$.

Striving for self-education and self-development is very important (58.0\%). The leading positions also share such skills as problem-solving (46.8\%), own opinion (32.8\%), and independent decision-making (48.0\%). Just as important, however, are communication (46.8\%), interpersonal skills $(34.8 \%)$, and collaboration (47.2\%). Creativity (44.0\%), attention to details $(30.0 \%)$ and adaptiveness $(32.0 \%)$ are also crucial for ITspecialists. While the physical qualities (18.0\%), and leadership (18.8\%) is not greatly appreciated, but also desirable. 


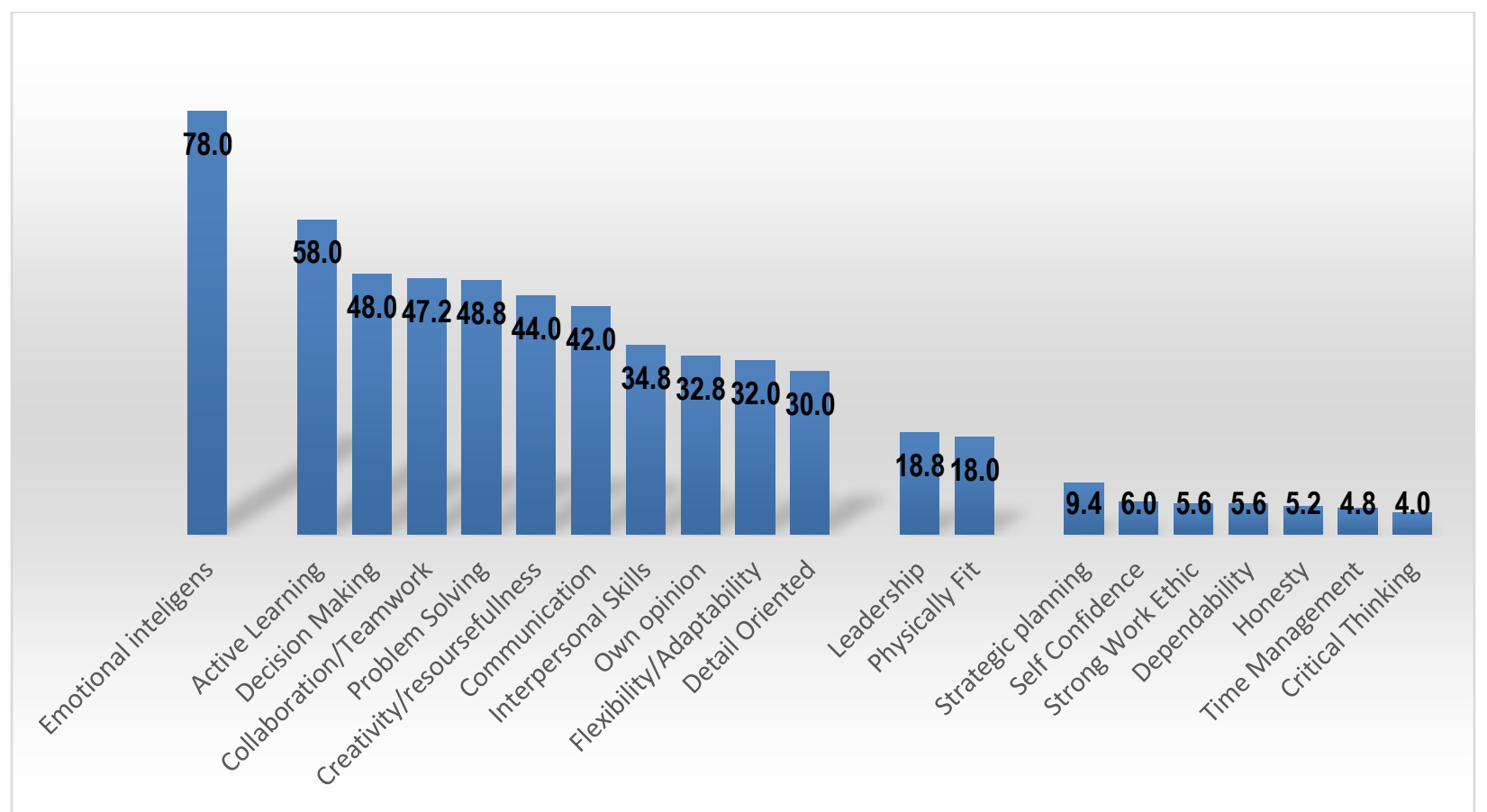

Figure 1. Professionally important soft skills for IT-specialists.

Strategic planning (9.4\%) is somewhat lower than professional career building. Consolidation of literature data has resulted in identification of several parameters that are professionally important for IT-specialists (Figure 2), although rarely mentioned by foreign professionals. But native professionals pay great attention to these (psychophysical) qualities.

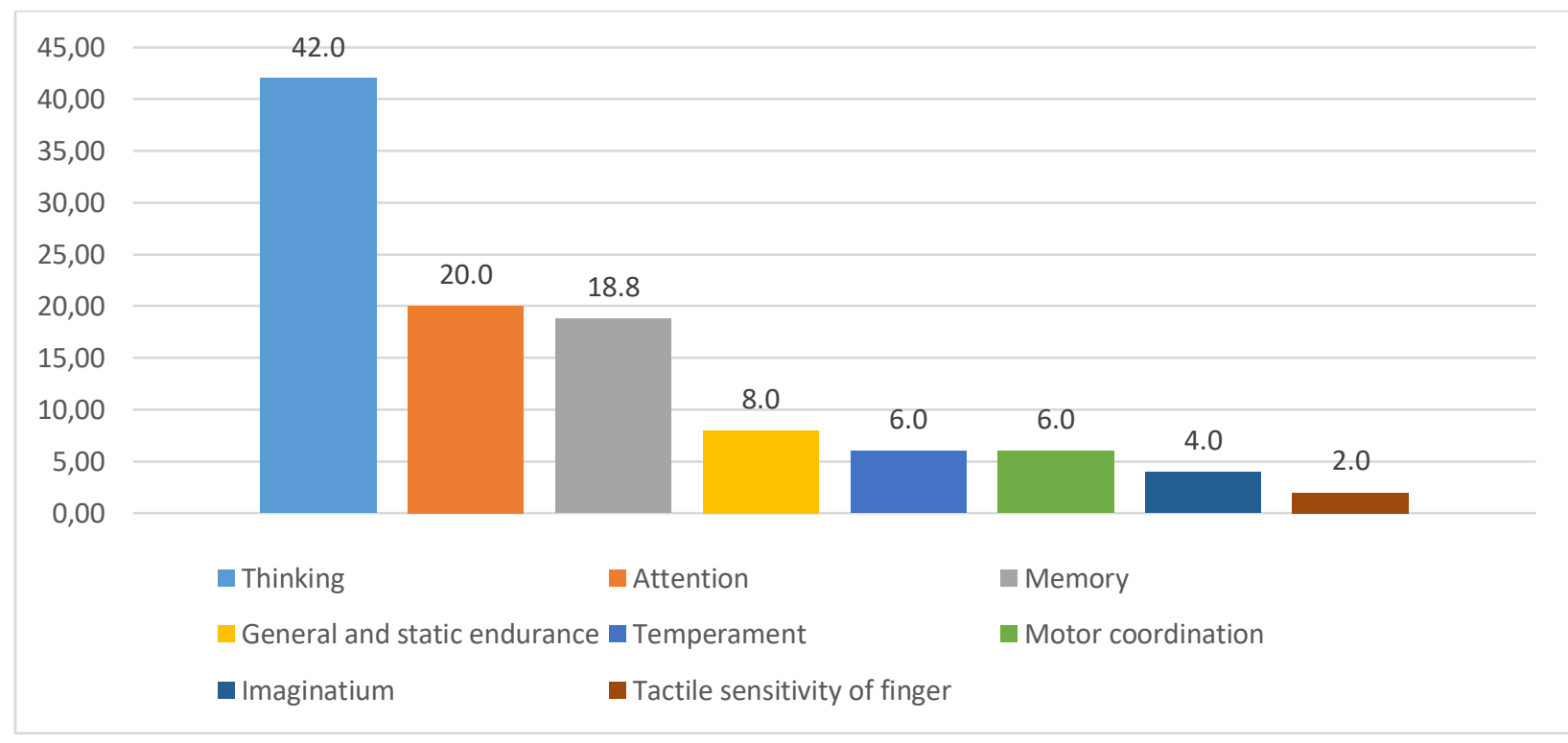

Figure 2. Psychophysical qualities professionally important for IT specialists. 
As you can see, this group includes cognitive skills (thinking $-42.0 \%$, memory $-18.8 \%$, attention $-20.0 \%$, imagination $-6.0 \%$ ), which are typical for the intellectual professionals; psychophysical parameters (general and static endurance $-8.0 \%$, tactile sensitivity of fingers and motor coordination - by $2.0 \%$ ), which are dependent upon the productivity of IT specialists; as well as temperament (6.0\%).

\section{DISCUSSION}

Professionally important skills - or hard skills - are formed in the process of teaching the core curriculum. But by means of physical education one can create a basis for their development - to form a general physical preparedness. It is possible to create a basis for their development by means of physical education (PE) e.g., to form general physical preparedness. It will provide the foundation for the development of a number of important professional qualities, will help to reduce fatigue and increase working capacity, which will allow better perception of educational material in the professionally oriented curriculum. Having considered the low level of physical and psychophysical training of IT students and the dynamics of deterioration over the years of training (Martinez-Lopez et al, 2019; Martinez-Lopez et a, 2012), as well as the negative influence of computer work on the health of IT-specialists, it has been recommended to intensify physical activity during academic classes for students in order to improve the level of general (basic) physical preparedness. That is also the view of other scholars (Culpeppe et al, 2015; Zhou et al, 2018; Martinez-Lopez et al, 2019). However, it should be kept in mind that strenuous physical activities do not contribute to the manifestation of cognitive abilities (Egger et al, 2018). Therefore, it is recommended to increase the number of PE classes in the course of the week. It is known (Kim et al, 2012) that 3 or more PE classes per week contribute to improving cognitive qualities, whilst reducing the number of classes leads to their deterioration. Sports activities can be also recommended as supplementary to the compulsory ones. The soundness of that recommendation has been reconfirmed by the relatively higher level of physical development among student athletes (Salatenko et al, 2015; Pichurin, 2018; Kostyunin, 2014).

Hard skills are important when employing successful candidates, however, over time they lose their importance in favour of "soft skills". Thus, it is proved (Kappelman et al, 2016) that the value of technical skills of IT-specialists and their awareness of key competencies gradually diminishes (from $47 \%$ to $2.5 \%$ and from $23 \%$ to $15 \%$ correspondingly) with the improvement of their professional skills. Actually, soft skills that are important for any work form a good employee. That is why most employers $(57 \%)$ appreciate good soft skills in their employees rather than their hard skills. Some experts have argued that demand on soft (flexible) skills has been increasing since 1980 (https://zety.com/blog/hard-skills-soft-skills).

Almost all the soft skills that are important for IT-specialists can be formed with help of going in for sports. It is well-known that individuals with long experience of being involved in the activities of sports sections have a higher level of development of such personal qualities as strive for self-improvement, autonomy, leadership, sociability, etc. That is why sports experience can be a crucial one at employing the successful IT candidate.

The generalization of the soft skills important for the professional development of IT-specialists showed that the most important of them can be logically grouped into four groups. Critically-important qualities form the first group. The only one feature has been appointed to the group - emotional intelligence (ability of an individual to handle emotional information and use it for navigation in social environment) (78.0\%). However, it is the only one that combines several skills: high level of social intelligence, introspection, high level of emotional self-control, and developed communication skills. Yoga (Tolcheva, 2011) can effectively facilitate the improving of inner controllability, resilience in coping with stress, the ability to control their behaviour in interpersonal relationships. 
It has been determined that IT professional's desire for self-education and development, as well as active life-long learning (58.0\%) is the most important quality. Our figures on the primary importance of continuous learning is confirmed by other experts (Kranov et al, 2015), as well as by employers. Thus, IT managers provide the highest importance rates to the signs of self-education and development when assessing the degree of professionalism. Yet, the question remains whether the means of physical education can contribute to the development of the desire for self-education and self-improvement, and which are the most effective ones.

Decision making (48.0\%) and problem solving (46.8\%) are the leading skills that hold the second position in our rating list. At the same time, scientists (Kappelman, 2016) have pointed out that the relevance of problem solving skills decreases (from $40 \%$ to $20 \%$ and $6 \%$ ) with growth of IT professionals' hard skills. Instead, the value of decision-making skills substantially increases (from $2.5 \%$ to $10 \%$ and $23 \%$ ). Some studies have found that regular physical activity is useful for developing decision-making skills (Sone et l, 2017). However, data on the types of motor activity that contribute to decision making and problem solving skills are not available. This requires further research on this topic.

Team working (47.2\%), interpersonal skills (34.8\%) and communication (42.0\%) are the third among the most important ones. It has been established (Hendon et al 2017) that emotional intelligence and the degree of communication are closely connected among IT-specialists. It is important that the value of team working skills practically does not change with experience (from $38 \%$ to $35 \%$ and $20 \%$ ), and even the value of verbal communication skills somewhat increases (from 18\% to 22\%) (Kappelman et al, 2016). Importance of building relationships with other people and managing them substantially increases with the increase of hard skills (from 0\% to 30\%) (Kappelman et al, 2016). Findings indicate that team sports can contribute to the formation of group cohesion (Brinkley et al, 2017). In this way, we have verified a leading role of learning (Kranov et al, 2011), decision-making and problem solving (Kappelman et al, 2016) skills, as well as communication, team-working, and people management (Kappelman et al, 2016) skills for successful work in the IT field. For the first time, we have determined that the leading IT-specialists have the following skills: own opinion (32.8\%), creativity $(44.0 \%)$, attentiveness to details $(30.0 \%)$, flexibility / adaptiveness $(32.0 \%)$. There are no data available concerning the question whether physical activity contributes to such important in terms of IT-specialist's work aspects as creativity, leadership, strategic planning, etc. That requires an indepth study of the topic.

Leadership (18.8\%), adequate level of physical conditions (18.0\%), and strategic planning (9.4\%) are desirable for successful professional experience. Scientists (Collin et al, 2018) have confirmed dependency of working efficiency of IT-specialists on their leadership and creative skills. Moreover, they (Kappelman et al, 2016) have pointed out an increase in the significance of IT-specialists' leadership skills (from $0 \%$ up to $7 \%$ and $35 \%$ ) with improvement of their qualifications. It's important to keep in mind that usefulness of strategic planning skills also increases (from $0 \%$ up to $25 \%$ ) with working experience (Kappelman et al, 2016). It is well-known and established that regular physical educational training contribute to the improvement of physical development and adaptation to unfavourable environment.

As a result of research, an additional group of IT-specialists' hard skills has been identified. This group includes cognitive skills (thinking, memory, attention, and imagination), psychophysical parameters and temperament. These skills belong neither to any group of technical skills (or hard skills) that are important for a specific profession, nor to the behavioural skills (or soft-skills) required in all professions. Although, it is true that variations of these qualities are regarded as soft skills in accordance with some sources. 
We have found that thinking $(42.0 \%)$, attention $(20.0 \%)$, and memory $(18.8 \%)$ increasingly define the professional success of IT specialists. Thus, it has been confirmed (Ostapenko, 2015) that attention, thinking, and memory are the most important psycho-physiological skills for IT-specialists. Analytic-synthetic thinking (Tolcheva, 2011), flexibility (Misra et al, 2018), efficiency (Waraporn, 2015) and criticism (Mardis et al, 2018) are generally considered to be significant characteristics for IT professionals. So, our findings correlate with the data (Waraporn, 2015) on the importance of operational thinking for IT professionals. It has been proved by scientists (Salatenko et al, 2015) that volleyball has positive influence on mentation, the rate of mental processes and mental capacity.

While dealing with attention, the following requirements should be taken into consideration: attentional capacity, attention span, attention rate, as well as high attention focusing, sharing and switching rates. The studies (Ostapenko, 2015) have confirmed that important figures for IT professionals are attentional capacity, sharing and span of attention. The increase in the overall level of physical development of students, and especially the improvement in performance of student's "shuttle run $4 \times 9$ meters", significantly affects their level of development of attentional selectivity (Pichurin, 2018). Thus, it has been proved once again (Ostapenko, 2014) that dexterity exercises improve the concentration and span of attention. Hatha-yoga (Tolcheva, 2011) works towards improving the perception and speed of information processing under difficult time constraints. Bodyflex and Pilates applications contribute to increased mobility and strength of neural processes (Kozina et al, 2014).

Memory is required to have the following characteristics: capacious, verbal-logical, long-term, operational or short-term. Our data are in line in terms of importance for IT professionals of short-term and long-term memory. Volleyball (Salatenko et al, 2015) has been proved to have a positive influence on short-term memory.

So, cognitive parameters are well-adjusted in the process of physical education. Sports games, hatha yoga, Bodyflex and Pilates (Pichurin, 2014; Salatenko et al, 2015; Kostyunin, 2014) have worked well in developing the cognitive qualities of students. These tools should be applied in classes to improve the cognitive performance of IT students.

Our records show (see Figure 2) that the following psychophysical skills are important for IT-specialists: "tactile sensitivity of fingers", and "arm-hand steadiness and hands stability (low tremor)" (Pichurin, 2014), and potential for long-term intensive mental activities against low and monotonous physical activity (Pichurin, 2014; Kozina et al, 2014). To improve coordination, it is advisable to recommend exercises that require clear spatial and temporal movements, as well as muscle regulation, which reveals the relationship between direction, speed, duration, muscular effort and its outcome. Following exercises are recommended for improving spatial orientation: exercises for fast and accurate execution of "contrast" tasks in space; physical exercises with limitation of visual control; exercises with pronounced influence on one of the analysers with the help of tempo leaders; the use of lighten or complicated conditions while performing various ballistic exercises, distance differentiation exercises, and specific game-playing activities. Other exercises are advised for increasing feelings of efforts: physical exercises involving dosed out efforts, with variations of strain or size and weight of additional items, exercises on simulators with burdens, etc. For the development of the ability to sustain an intensive mental strain for a long time, specialists recommend the development of aerobic endurance. Studies have shown that good aerobic endurance has a positive correlation with memory and other cognitive functions. Continuous load of chain exercises (over $12 \mathrm{~min}$.) within the threshold of anaerobic change (TANC) are referred to as means of development. 
When applying for a job in IT industry, it is important to consider the type of temperament (9.4\%) of the ITspecialist. Other professionals also share the same view (Pichurin, 2018). Temperament indicators are included into the package of standardized diagnostic methods for perspective of IT specialist's professional development. It also confirms the importance of temperament in IT specialist's career growth. All in all, temperament can't be altered. However, taking into account the type of temperament, it is possible to choose sports that would be consistent with the requirements of the individual. It is known that the increase in the overall level of student's physical development significantly reduces the level of personal anxiety (Pichurin, 2018). However, the peculiarities of temperament, important for progress in the IT industry, have not been established.

\section{CONCLUSIONS}

1. All soft skills can be divided into three groups: very important, leading, desirable. It has been found that such skills as emotional intelligence $(78.0 \%)$ are crucial for IT-specialists; whereas the leading skills are: studying ability and strive for self-education and self-improvement $(58.0 \%)$, independent decision making $(48.0 \%)$ and problem solving (46.8\%); establishing communication $(42.0 \%)$ and team-working (47.2\%), interpersonal skills $(34.8 \%)$; creativity $(44.0 \%)$, attention to details $(30.0 \%)$, and adaptiveness $(32.0 \%)$. An adequate level of physical conditions and leadership are regarded as desirable (18.0 - 18.8\%).

2. The level of importance of psychophysical parameters for IT professional's work efficiency has been determined: cognitive parameters (thinking $-42.6 \%$, memory $-18.8 \%$, attention $-20.0 \%$, and imagination $6.0 \%$ ), psychophysical qualities (general and static endurance $-8.0 \%$, tactile sensitivity of fingers $-2.0 \%$ and motor coordination $-6.0 \%)$, and temperament $(6.0 \%)$.

3. To form professionally important skills IT-specialists we are recommended to use measures to promote agility and mental fitness. Such means of physical activities have worked well in the development of cognitive qualities of students. Also, to form professionally important skills IT-specialists have been recommended to reinforce the workload on physical education sessions, increase the number of academic classes on physical education up to 3 per week, or supplement academic activities with sports.

4. In professional literature, there has been found no datum on the type of motor activity that encourages forming a number of leading professionally important skills (such as strive for self-improvement, decision making and problem solving, as well as creativity, leadership, and strategic planning). This requires further research on this topic.

\section{SUPPORTING AGENCIES}

No funding agencies were reported by the author.

\section{DISCLOSURE STATEMENT}

No potential conflict of interest was reported by the author.

\section{REFERENCES}

Andres, A. (2018). Psychophysical preparedness of students of the specialty "Computer technologies", Physical activity, health and sports. 1 (31):3-9. 
Andres, A. (2019).Dexterity and attention indicators of students of the Institute of Information Technology. Physical education, sports and health care in modern society, 1:3-9.

Andres, A.; Fedak, O.; Maximyak Y. (2019). Professionally important qualities of specialists in the field of information technologies and their formation by means of physical education. Sports Science of Ukraine, 1.

Brinkley, A.; Mcdermott, H.; Munir, F. What benefits does team sport hold for the workplace? (2017). A systematic review. Journal of Sports Sciences, 35 (2):136-148. https://doi.org/10.1080/02640414.2016.1158852

Collin, K.; Herranen. S.; Paloniemi. S. et al. (2018). Leadership as an enabler of professional agency and creativity: case studies from the Finnish information technology sector. International journal of training and development,22(3): 222-232. https://doi.org/10.1111/ijtd.12130

Culpeppe, D.; Killion, L. (2015). It's Not Me, It's You: The Disconnect of Physical Education Teachers to Physical Activity in the Gym. Sports, 3(4):302-311. https://doi.org/10.3390/sports3040302

Danaher, M.; Schoepp, K.; Kranov, A. (2016). ABET's professional skills in computing. World Transactions on Engineering and Technology Education, 14(3):213.

Egger, F.; Conzelmann, A.; Schmidt, M. (2018). The effect of acute cognitively engaging physical activity breaks on children's executive functions: Too much of a good thing? Psychology Of Sport And Exercise, 36:178-186. https://doi.org/10.1016/j.psychsport.2018.02.014

Hendon, M.; Powell, L.; Wimmer, H. (2017). Emotional intelligence and communication levels in information technology professionals. Computers in Human Behavior, 71:165-171. https://doi.org/10.1016/i.chb.2017.01.048

Hlazunov, S. I. (2016). Peculiarities of military officers' physical perfection during troops' being in conditions of positional defense, Pedagogics, psychology, medical-biological problems of physical training and sports, 20(1):13-18. https://doi.org/10.15561/18189172.2016.0102

Kappelman, L.; Jones, M.; Johnson, V.; Mclean, E.; Boonme, K. (2016). Skills for Success at Different Stages of an IT Professional's Career. Communications of the ACM, 59(8):64-70. https://doi.org/10.1145/2888391

Kim, S.-Y.; So, W.-Y. (2012). The Relationship Between School Performance And The Number Of Physical Education Classes Attended By Korean Adolescent Students, Journal Of Sports Science And Medicine, 11(2):226-230.

Kostyunin, A. (2014). Determination of indexes of psychophysiology qualities for the students of universities of different courses that engage in futsal in the process of extracurricular work. Pedagogics, psychology, medical-biological problems of physical training and sports. 18(7):18-22. https://doi.org/10.6084/m9.figshare.1015380

Kozina, Z.; Ilnitskaya, A.; Paschenko, N.; Koval, M. (2014). Integrated application of health improving methods of Pilates and Bodyflex for improving psychophysiological possibilities of students. Pedagogics, psychology, medical-biological problems of physical training and sports, 18(3), pp. 31 36. https://doi.org/10.6084/m9.figshare.936963

Kranov, A.; Zhang, M.; Beyerlein, S.W.; et al. A direct method for teaching and measuring engineering professional skills: A validity study, AM SOC ENG ED A, Accessed 3 November 2015. URL: http://www.asee.org/public/conferences/1/papers/775/view (accessed 2019 May 31).

Lisowski, V. O.; Mihuta, I. Yu. (2013). Importance of coordination skills essential psychophysical demonstrated competencies as a military specialists. Physical Education of Students, 6:38-42. https://doi.org/10.6084/m9.figshare.840501

Mardis, M.A.; Ma, J.; Jones, F.R. et al. (2018). Assessing alignment between information technology educational opportunities, professional requirements, and industry demands Educ Inf Technol, 23:1547. https://doi.org/10.1007/s10639-017-9678-y 
Martinez-Lopez, E.J.; Grao-Cruces, A.; De La Torre-Cruz, M.J, et al. (2019). Associations Between Physical Fitness And Academic Performance In Teenagers South African. Journal For Research In Sport Physical Education And Recreation, 41 (1):63-75.

Misra, R.K.; Khurana, K. (2018). Analysis of Employability Skill Gap in Information Technology Professionals. International Journal of Human Capital and Information Technology Professionals, 9(3):53-69. https://doi.org/10.4018/ijhcitp.2018070104

Ostapenko, Y. (2014). Professionally significant psychophysiological qualities of information logical group of specialties at implementation of the experimental program of professionally applied physical training of students. Pedagogics, psychology, medical-biological problems of physical training and sports, 18(4):34-39. https://doi.org/10.6084/m9.figshare.951918

Ostapenko, J.O. (2015). Professional-applied physical training of students of the information-logic group of specialties. Cand. Diss., Kyjiv, 2015, 222 p. Ukrainian.

Pichurin, V. (2014). Psychological and psycho-physical training as a part of physical education of students in higher educational establishments. Pedagogics, psychology, medical-biological problems of physical training and sports, 18(11):44-48. https://doi.org/10.15561/18189172.2014.1108

Pichurin, V. (2018). Theoretical and methodological foundations of psychophysical training of students of engineering specialties in the process of physical education. Diss., Kyiv, Ukrainian.

Salatenko, I., Dubinskaya, O. (2015). Psycho-physical perfection of economic specialties' girl students under influence of sport-oriented technology, based on prevalence of volleyball practicing. Pedagogics, psychology, medical-biological problems of physical training and sports. 19(12):103108. https://doi.org/10.15561/18189172.2015.12016

Soft Skills vs Hard Skills for a Job: What Employers Look for (+Lists) https://zety.com/blog/hard-skillssoft-skills (accessed 2019 May 23).

Sone, T.; Kawachi, Y.; Abe, C.; Otomo, Y., Sung, Y. W.; Ogawa S. (2017). Attitude and practice of physical activity and social problem-solving ability among university students. Environmental health and preventive medicine, 22(1):18. https://doi.org/10.1186/s12199-017-0625-8

Tolcheva, A.B. (2011). Evaluation of the psychophysiological state of female students with experience in Hatha Yoga. Pedagogics, psychology, medical-biological problems of physical training and sports, 11:128-131.

Waraporn, J. (2015). Using individual values of information technology professionals to improve software development management practices in thailand. Asian Academy Of Management Journal, 20(1):4969.

Zhou, Z.; Dong, S.; Yin, J., et al. (2018). Improving Physical Fitness and Cognitive Functions in Middle School Students: Study Protocol for the Chinese Childhood Health, Activity and Motor Performance Study (Chinese CHAMPS) International Journal Of Environmental Research And Public Health, 15 (5) Article Number: 976. https://doi.org/10.3390/ijerph15050976

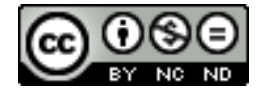

This work is licensed under a Attribution-NonCommercial-NoDerivatives 4.0 International (CC BY-NC-ND 4.0). 